\title{
Using social media in the news reportage of \\ War \& Conflict: Opportunities and Challenges
}

\section{Vittoria Sacco}

Academy of Journalism and Media, University of Neuchâtel

vittoria.sacco@unine.ch

\section{Diana Bossio}

Faculty of Health, Arts and Design, Swinburne University of Technology

dbossio@swin.edu.au

\section{KEYWORDS:}

Social media, war \& conflict, journalistic practice

\section{ABSTRACT}

Based on interviews with Swiss journalists who specialise in war and international reportage, this article investigates the extent to which social media impacts on reportage of war and conflict. The interviews examine journalists' perceptions of the threats and opportunities posed by use of social media in reporting conflict, by investigating how journalists position themselves and their practices within this new media ecosystem. In particular, the interviews explore whether challenges to professional journalism encountered in previous studies of reportage of war and conflict are overcome by the use of social media. It explores if social media can mitigate the effects of military and government restriction of information, changing newsroom dynamics and issues of audience engagement in reportage of conflict. The findings highlight that in the context of war and conflict, the dynamism of social media creates opportunities for fast news dissemination, pluralised voices in reportage and extended audience reach. However, reporters must also negotiate the complexities that fast, multi-medium and multi-sourced information create for reportage, especially in terms of the verification and contextualisation of information. Thus this article argues that although social media adds dynamism to journalistic environments, this dynamism also brings new levels of complexity to journalistic practice that professional media workers must negotiate. 


\section{INTRODUCTION}

Journalists have always had a place on the battlefield. As the eyewitnesses of war and conflict, they report first-hand the experiences of those engaged in the confrontation, as well as those who suffer its consequences. Historically, journalists have worked at, or close to, the scene of war and conflict. Foreign correspondents, stringers and other international media workers have worked with activists, governmental sources and non-governmental or charitable organisations to report the news of war and conflict to audiences far from the crisis. The significance of good journalistic work-and the importance of independently verified news and information during war and conflict overall-has not changed. But in a globalised, digitised and online world, the way in which both journalists and audiences experience and engage with news about war and conflict has changed. Increasingly globalised economic, migratory and media environments have brought otherwise distant and disparate people closer to war's touch (Sylvester, 2011). These globalised conditions have also meant the economic rationalisation of journalistic work; news agencies and freelancers have replaced the foreign news desks, and the numbers of correspondents dedicated to reportage of war and conflict to international audiences has dwindled. Where tradition- al news and information producers have decreased in number in some places, the number of information networks has nonetheless increased. Digital online and social media have allowed these otherwise disparate audiences not only to talk directly to journalists, but also to each other in multi-faceted conversations in real time. The advent of new devices and online social networks has thus furthered the spread of journalistic information, but also the number of voices producing news and information in the public sphere. This has also brought dramatic changes to the journalistic environment in which journalists do their work. While much media and academic discourse has lamented the "death" of traditional reportage and international news desks (e.g. Sambrook, 2010; Moeller 1999), more recent discussion has also focused on the possibilities of social media networks for reportage of international war and crisis (e.g. Zhang, 2013; Otto \& O Meyer, 2012). The interactions between journalists and different activists during the recent so-called "Arab Spring" protests have been a recent example of both the hope and hyperbole that the use of social media engenders. This contribution resides somewhere in the middle: it seeks to understand the challenges and possibilities for mainstream journalists attempting to bring news and information about war and conflict in distant countries to their local (and sometimes global) audiences. Taking these recent discussions of journalistic use of social media as a starting point, this article seeks to explore whether reportage of war and conflict has changed since the advent of social media use by journalists. More specifically, the study will investigate journalistic understanding of the potentialities and challenges of the incorporation of social media into reportage of war and conflict. This will highlight various dimensions from established practices to innovative work patterns. The interviews focussed on journalists' experiences of the effects of social media on their reporting practices. Swiss media organisations usually do not have the budget strength of organisations like the $\mathrm{BBC}$ or $\mathrm{CNN}$ to resource journalists when conflicts happen. Resources are also scarce because only a few journalists in Switzerland have had the right training to cover war. Finally, the crises that hit media companies all over the world have also affected Swiss media, engendering budget cuts, especially in foreign bureaus. This has led the coverage of foreign news in Switzerland to rest mostly on news agencies, other foreign media companies and online sources. It is particularly this last point which is of great relevance for this study, as Swiss journalists may have developed innovative ways to work with social media content to cover foreign news. 
The literature section presents existing research about conflict reporting and shifts in the coverage due to the advent of social media. The next section concerns the interview methodology and the selection of the sample. Finally, the findings section illustrates the argument that social media adds dynamism to journalistic environments at a time when both the production processes and audience engagement with news and information is changing. Nonetheless this dynamism also adds new levels of complexity to journalistic practice that professional media workers must negotiate-with varying results depending on context and expertise.
LITERATURE REVIEW: WAR, CONFLICT AND JOURNALISTIC WORK IN THE DIGITAL AGE

The evolution of the newsroom in an increasingly complex media environment deserves careful comparative analysis. The changing dynamics of reporting practice during war and conflict is of particular interest because it is often a period of demanding, yet important journalistic practice; journalists are working in situations where time and resources are restricted, doing physically demanding and at times dangerous work, but with an important news imperative-gaining information not just for their own audiences, but for those most impacted by the situation. Scholars in communication, media and journalism have also paid great attention to issues in reporting war because of the dramatic nature of events and relevance of reportage for states and publics, as well as the investment by media organisations in terms of resources and time to cover those events (Tumber, 2009, p. 386). Recent studies have emphasized the need for further research about how journalists cover war and conflict in terms of content and source selection; how images and depictions of the different parties engaged in a conflict are represented; as well as economic, political, social and cultural impact of war reportage at a local and global level (e.g. Robinson et al., 2009).
In this article, war and conflict are defined as an unexpected and overwhelming event that threatens the lives of a number of people (Thelwall \& Stuart, 2007).

Traditional issues in the reportage of war and conflict

Traditional academic study of reportage of war and conflict has centred on still-pertinent challenges to professional journalism: namely, the effects of military and government restriction of information, changing newsroom dynamics such as centralised news production and issues of audience engagement with reportage of conflict over time. Historically, journalists working during conflict have also experienced difficulty in negotiating government censorship and military control. Academic study has revealed issues associated with embedded journalism, as military and government officials become more adept at "handling" media requests for information during conflict. These processes find their raison d'etre in the apparent safeguarding of military personnel, as well as their own strategic and ideological objectives (Robinson et al, 2010). However, academic study has showed that this type of restriction also has the effect of whitewashing information available to journalists to report about war and conflict. Issues that emerge from embed- 
ded journalism are thought to include less critical engagement with the work of military personnel (Morrison, 1994) and an increase in the use of patriotic frames when covering conflicts (Bromely, 2004).

Another key challenge illustrated in more recent academic study is the new restrictions placed on newsrooms and journalists' "routinized" work (Tuchman, 1978). Economic and cultural pressures have meant that journalists have been forced to take "short cuts" when collecting information. This has meant stories have quoted only the sources that journalists have had the time to consult in keeping up with the demands of a 24-hour newsroom, where large, global news organisations expect around the clock updates and opinions on crises to unfold in real-time (Campbell, 1997; Gaunt, 1990). The issues that have emerged from the changing newsroom included such narrowing of information sources, as well as the privileging of some sources and information over others, and increased pressure on journalists. Much academic research (e.g. Hodgkins, 2002; Kendrick, 1994) has analysed CNN's video reportage of the Desert Storm operations during the Persian Gulf War in 1991 as the best example of issues arising from embedded journalism and changing newsroom pressures (Reese, 2011). Described as "war as in- fotainment” (Kellner, 1992), the images produced during operation Desert Storm seemed to promote a patriotic "good" versus "bad" narrative, veiling the war's cultural and political complexities to fulfil the opinion, commentary and video imagery needs during 24-hour coverage. During the wars in Iraq mainstream media organisations were criticised for stereotypical representation of Muslim people and simplistic news coverage (Cottle, 2011b). However, it was perhaps the 9/11 terrorist attacks that illustrated the globalisation of reportage of conflict, and the issues created by simplistic narratives and representations in the news such as the "Global War on Terror" coverage with spectacular imagery and reportage of emblematic, theatrical events (Cottle, 2008).

Given the increased "infotainment" value of news coverage, especially in broadcasting and online news, a related issue of audience engagement with war and conflict reportage has also emerged in academic study. Moeller (1999) has suggested that international journalism is in decline partly due to audience "compassion fatigue". The notion of "compassion fatigue" suggests an audience's decreased concern over time for international affairs and the way that these events are covered by mainstream media. Journalistic reportage has the potential to stress particular forms of engagement contributing to a mobilisation of publics and the creation of a collective memory amongst audiences (Ibrahim, 2010: 122). Equally being exposed on a daily basis to distant suffering can create a sense of apathy and disengagement within the audience, which results in "compassion fatigue" (e.g. Ibrahim, 2010). These challenges have been utilised as the basis of interviews with Swiss journalists to explore whether social media might overcome some of these issues; however some preliminary academic research on the use of social media has also been utilised as a framework for interview discussion.

Social media use in reportage of war and conflict While issues of media restriction, increased pressure and disengaged audiences continue to challenge war reportage, the changes brought by the emergence of digital, online and social communication networks have affected all realms of journalism, including war reportage. Indeed, journalistic use of social media can be seen within the framework of media innovation studies more broadly, as these new technologies and applications represent process innovations as they are implemented in journalistic practices (Dogruel, 2014: 57). According to Bruns (2014, p. 13) "media innovation is an innovation in media practices at least as much as in media technologies", having an impact on both 
media practices and societal changes. This is particularly relevant for journalistic work during conflict and war. The recent "Arab Spring" protests in Middle Eastern countries for example, show evidence of new forms of reportage of conflicts, including an increased diversity of news sourcing techniques, the inclusion of grassroots and citizen journalism in mainstream reportage and blog and opinion content being disseminated on global micro-blogging networks such as Twitter and Storify (Reese, 2011). During the "Arab Spring", loose cooperation between those who witnessed and those who reported (i.e. the media) illustrated new possibilities for democratisation of media space during a conflict. For example, mainstream news organisations integrated links to other platforms like blogs, videos and tweets from other voices in the public sphere, constantly spreading breaking news from the heart of the protests (Cottle, 2011a, p. 298). During the Tunisian, Egyptian and Syrian protests, social media was seen to play a "watchdog" role in ensuring that state controlled media did not disseminate false information to global audiences. International news organisations also disseminated eyewitnesses' social media content back into the repressive states to inform local audiences. These changes relate to previous research about media innovation that emphasises the co-creation by us- ers and producers of products, platforms, and practices, which contribute to societal change (Banks 2013, Bruns, 2008).

While some have proclaimed the new "democratisation" of the media with the onset of user generated content and increased social media use, others have cited issues of surveillance, incorrect and hoax reporting and subjective information. A. Hermida (2009) has suggested the editorial values of accuracy, impartiality and fairness cannot cohere with the immediate, uncensored and unmediated flow of information of the blogosphere. Another such issue is associated with social media's capacity to undermine the gatekeeping function of journalists (Hermida, 2010). Scholars have pointed out that the boundaries between witnesses and journalists are blurring (e.g. Andén-Papadopoulos, 2009; Allan et al., 2007) and citizens' online news dissemination can work in competition with journalistic work. The contradictory reports, rumours and/or speculation that can be spread quickly and globally on social media bring also additional challenges (Hermida, 2012). A final issue is that the increased reliance on social media may lead to an increasing homogenization of journalism (Nygren, 2014). Fieldwork is less present in the everyday routines of journalists who spend most of their time in front of their computer (Lee-Wright \& Philips, 2012).
More time is dedicated to production for different channels and the recycling of content for different formats (Nygren, 2014, p. 94). The ambiguous relationship between social media and the coverage of foreign news underlines the need for further research. In particular, in-depth investigation is necessary to fully understand the complex dynamics behind this relationship. 


\section{JOURNALISTS}

Taking these varying viewpoints about the use of social media during war and crisis as a starting point, this article investigates journalists' perceptions of how their reportage of war and conflict has been affected by the inclusion of social media use in their practice. The investigation poses the following research question:

What is the impact of social media on the practices of mainstream journalists in investigating and reporting cultures for newsrooms when reporting war and conflict?

To investigate this question, journalists and other editorial staff working in fields of foreign correspondence and war reportage were interviewed about examples in their own work that illustrated the possibilities and challenges posed by the use of social media in reporting war and conflict. The study then examined the strategies employed by editors and journalists, exploring both their normative reporting practices and their use of social media in reporting crises to compare their perceptions of change with actual changes in their practice.

Existing research has followed similar lines of enquiry (e.g. Cottle, 2011a, 2011b; 2008; Sam- brook, 2010), though these projects have focussed mainly on US and UK mainstream media. Swiss journalists were selected because they might provide different data from existing research. Switzerland is a country with a small media system, whilst also having a diverse population, a wealthy economy and geographical distance from major conflict areas. Swiss journalists work in small newsrooms, away from crisis, though with a diverse audience, and might thus offer an interesting perspective on social media use. Although the data is to be generalised from the Swiss perspective on journalism, this article attempts to highlight the more broadly applicable practical and social issues regarding the overlap of traditional journalism and social media generated reportage. The ethical and professional issues raised in these interviews can thus be applied to other newsrooms that follow the liberal tradition of journalism and that also face the challenge of integrating social media into their reporting practices. In other words, in a highly globalized world the issues raised by Swiss journalists about the use and abuse of social media and its inter-penetration with journalism may have relevance elsewhere.

The interviewees were comprised of 22 journalists of major Swiss media companies, covering print, TV and radio. They were predominantly males (20). They were mainly involved in coverage of foreign news. They ranged from correspondents with more junior profiles (average age around 30 years old) to heads of foreign news (average age around 50 years old) with more senior and editorial work profiles. In addition, journalists who worked in multimedia and online sections were also interviewed. This was necessary because these journalists interact daily with all the other news sections. Furthermore, they monitor activity on social media as well as taking responsibility for social media accounts associated with their media company. Similarly, journalists from the national press agency were included in the sample because they also report using social media. Moreover, they sometimes work as the intermediaries between Swiss media companies and other foreign media companies. The sample also attempted to represent the morphology of Switzerland, which is composed of different official and national languages; each linguistically different region has its own media and production policies. Table 1 reports the profiles of the participants.

The semi-structured interviews were organised around a list of selected open-ended questions, allowing the collection of standard information about the informants (Arksey \& Knight, 1999). The interviews were performed from February 2013 to May 2013, ranging from 38 minutes to 2 hours in 
length. Choosing interviewees might also be a limitation because all the respondents were journalists or marketers; and usually journalism "professionals" are regarded as having quite tightly-knit areas of conformity and social origin (e.g. O'sullivan \& Heinonen, 2008). To minimise the negative impact of this limitation on the result, the sample included several kinds of journalists who held different positions and had different ages and incomes. A last limitation of the interviews is their subjective nature, which can impact the interviewers if the interviewing and analysis phases were overly subjective, and the interviewees, if the answers to the questions were according to a subjective viewpoint or in a manner that would please the interviewer(s) (Hycner, 1985, p. 296). The structure during the interview and analysis phases can help to limit the first type of subjectivity (Hycner, 1985, ibid). The second type of subjectivity is less problematic because it can be valuable to investigate a phenomenon in terms of the personal experience of the respondent(s) (Hycner, 1985, ibid).

Table 1.

Interviewees' profile

\begin{tabular}{llll}
\hline Swiss Print & Radio/Television
\end{tabular}

Media

French

ESH Media Group (1): Head of multimedia and Online

La Liberté (1): foreign news correspondent

Le Temps (Tamedia Group) (2):

Head of foreign news \& Multimedia journalist

La Tribune de Genève (Tamedia Group) (1): Head of foreign news

German The Blick (Ringier Group) (1): Senior Editor of foreign news NZZ (AZ Medien Group) (1):Community Manager

Italian Corriere del Ticino (5): Head of foreign news \& Multimedia and Online Team (4 journalists)
TSR (National Public broadcaster) (3): Head of foreign news \& Head of Multimedia and Online \& Social Media Specialist

$S R F$ (National Public broadcaster) (3): Head of multimedia and Online \& Quality and Market Director \& Assistant Editor of foreign news

RSI (National Public broadcaster) (1): Head of multimedia and Online
UN Correspondent (1)

ATS (National Press Agency)

(2): Assistant Editor of foreign news \& Head of foreign news 
The literature section of this article illustrated the most recent debates about the use of social media in reportage of war and conflict, suggesting the dual role that social media can have in supplementing journalistic work. In completing the analysis of the interview data obtained from Swiss journalists, this article will first present the opportunities journalists suggested were apparent in using social media while reporting on war and conflict, and second, detail the challenges that the same journalists faced. This structure will assist in illustrating some of the overlapping complexities that journalists negotiate when they use, or rely on, social media to cover war and conflict.

Possibilities: from the improvement of capacity to audience engagement on a global scale

Much contemporary research has shown that journalists can potentially have direct access to many more sources of information on social media (Hermida et al., 2012), which has the potential to increase the diversity of perspectives and content in the reportage. Social media gives a space and more importantly, a presence, to those who were previously unseen or voiceless in the media sphere, or who were considered a negligible part of an oth- erwise packed news agenda (Otto \& Meyer, 2012; Reese, 2011). In the semi-structured interviews, one of the participants highlighted the importance of these new available voices on social media to increase diversity of reportage especially during a complex conflict situation:

Even if there are conflicts on which the audience and also journalists have absolutely no information, there is always one of the camps that manages to communicate. Social media can bring to light the images of the silent camp (Participant L, 9 April 2013).

On social media, the increased number of available voices with different experiences can support interaction between people and the representation of pluralised identities in the media. Furthermore, news narratives do not have to rely on the voices of "officials" or elites. Thus, social media might help to overcome in part the effects of military and government restriction of information during wartime. As reported by one participant, this was certainly evidenced during the "Arab Spring":

We must report as objectively as possible. But when you realize that there is total censorship, as was the case in Tunisia, you do not reach people but these people fail to react, to carry messages via tweets, you say this is what we must relay because censorship is an objective condition! (Participant H, 5 March 2013).

In sourcing the many voices that tell the story of war, however, journalists face many dangers and professional hindrances. According to Cottle (2008), the geographic access and the danger of travelling in conflict zones can sometimes hinder communication with those considered "opposition” or simply divergent voices. Many of the journalists interviewed underlined that through the use of social media they could cover more remote geographic areas that would otherwise not be reached, due to location, the cost of getting there or the suddenness of events. One participant suggested that this made a significant difference to foreign correspondents' reporting of other perspectives on conflict and war:

These tools allow foreign correspondents to follow and be followed by NGOs, news agencies, groups' pressures etc. It is a tool for them to improve the visibility of their work as well as to have direct access to sources and be aware of unfolding events. Through social media, they can reach more people. (Participant P, 10 April 2013). 
An example of this kind of social media use in action is journalists' reportage of the events of conflict in Libya in the initial days of the "Arab Spring". YouTube content was integrated into mainstream media for reporting the attacks on rebel forces in Libya during the 2011 conflict after journalists were banned from Libyan territory by the government (Cottle, 2011a). Cottle (2011a, p. 302) reported that the group were "dubbed 'The Global YouTube News Bureau" and they assisted by bringing "vivid images bearing witness to human rights abuses and impending humanitarian catastrophe circulated despite the absence of foreign correspondents on the ground. As they did, so calls were increasingly heard for those responsible to be pursued and prosecuted in the International Criminal Court".

Thus, the use of social media during war and conflict has a positive impact on professional practice when traditional investigative practices are compromised. However, newer research has also shown the influence of social media by demonstrating its integration into traditional work routines (e.g. Otto \& Meyer, 2012). Zhang (2013, p. 321) remarked that social media are an established part of journalists' work routines and are considered supplementary reporting tools. Similarly, in their analysis of the changing practices of journalists to cover the "Arab Spring", Bossio \& Bebawi (2013) illustrated that several journalists used Twitter to supplement their investigations. The interview participants noted that social media is complementary to traditional journalism practices; particularly as an alert when something newsworthy is going to happen. One participant used the example of the Egyptian "Arab Spring" protests to demonstrate the ways in which social media were integrated into traditional sourcing of news:

We also look at the general atmosphere. For example, after the assassination of the opposition in Egypt it would have ended there, except that suddenly we see the entire blogosphere that started to rustle in a way that might result into a protest. Here, there is no need to check the info, it is a mood. So we switch to the modality on alert" (Participant F, 12 February 2013).

This concept of an "alert" is related to the capacity of social media to keep journalists attuned to breaking news and real-time information when events unfold (Hermida et. al, 2012). This is extremely important as a supplement to journalists' traditional work routines in an age where lack of resources, smaller newsroom and 24-7 deadlines mean they cannot always be on location or covering each event during a conflict or war situation. In this context, one of the participants highlighted the importance of the immediacy of social media when covering unfolding events:

It is the immediacy of being able to find information but also contact sources. If you join sources on Twitter you have much more chance of reaching them directly than by phone or anything else" (Participant K, 12 March 2013).

This immediacy can help journalists to find relevant sources of information in a short time frame. In this way, journalists keep up with the demands of a 24-hour newsroom without obscuring the cultural or social complexities of a particular conflict situation. Beyond this, social media assists journalists in avoiding simplistic and stereotypical narratives and representations. For instance, one of the journalist interviewees maintained that social media can help people to become closer to different cultures as well as creating true solidarity movements:

The 'Arab Spring' could not be stereotyped because people saw the protesters on social media. The viewers saw that the protesters were people like them. In these cases, the content that spread on social media has a positive impact on people who are not directly affected by these events. This content can be com- 
pared with some of the photos published during the Vietnam War that contributed massively to strengthen the peace movement in the United States or the photos of Abu Ghraib that caused real scandals and later opened debates about the legitimacy of the Iraq War (Participant H, 5 March 2013).

Similarly, Joseph (2012, p. 153) used the example of the social media accounts of the daughter of Abdullhadi Al Khawaja, a human rights activist in Bahrain who was jailed for life in June 2011 for dissident crimes (@angryarabiya) to show how tweets reach a global audience in real-time. She concluded that social media information can be accessed by a large and geographically diverse audience and thus assist in furthering the audience's engagement in an otherwise ignored news story. Thus, the potential of social media is that it can assist in overcoming the problem of "compassion fatigue" because otherwise distant audiences connect with events in an intimate, first-hand narrative from eye witnesses, transported to them through the journalist's reportage.In this regard, one of the journalist respondents added that the spreading capacity of social media is also an advantage, especially for correspondents reaching an international audience:
Because they cover international news, several people over the world can be interested in the content of our correspondents, not only the usual readers of the newspaper. Also, they can reach a younger audience that is less attached to the paper format. Thus, social media help us to promote our stories and reach new audiences. (Participant P, 10 April 2013).

During the "Arab Spring" for example, protests, hand-held devices and social media were used to deliver content about breaking news events reaching people around the world (Eltantawy \& Weist, 2011). Through social media, citizens' productions reach a larger audience because the content is spread worldwide and users can access it instantaneously (Mortensen, 2011, p. 67). This was evidenced during the "Arab Spring" on key events such as the "Day of Anger" (25th January) followed by the "Day of Rage" and the "March of the Millions" (1st February) in Egypt, where amateurs' images reached international public and media attention (Cottle, 2011a, p. 294). Although social media has been seen to have the potential to overcome some of the limits placed on journalists in covering war and conflict, participants have also highlighted some limitations. The next section presents the dif- ficulties that journalists have to face when using social media in their reporting practices. This illustrates the various complexities that journalists negotiate when they rely on fast, multi-medium and multi-sourced information.

Issues: from misinformation to manipulation and audience distance

Despite the increased opportunities for journalists to enrich their reportage with the use of social media, there have been some complexities in the use of social media during conflicts that journalists have attempted to negotiate. These issues range from technical limitations, especially in terms of access to quality content, to the overall verification of information, which can lead to misinformation, manipulation or subjective reportage. This is because information spread on social media often does not match the standards of objectivity, independence and accountability to which journalists feel compelled, whether by law, or by professional codes of ethics, to conform (Hermida, 2012). This challenges journalists because social media requires time not only to be verified, but also to be found in the masses of content that is posted on various platforms. Therefore, journalists reporting on war 
and conflict have suggested that social media content requires deft skill in finding relevant information and contextualising often first- hand and subjective information. For Swiss journalists covering conflict from a distance, the biggest issue in using social media is finding a good quality of sources in terms of verifiable first-hand accounts of conflict:

Around the same time frame of the 'Arab Spring', all these events happened also in Iran but, we could not use user generated content. We were unable to say that it happens at a particular time or at a particular place. That is why the Iranian protests had less visibility in the news compared to the other events that shaped the Arab countries. (Participant G, 13 March 2013)

Similarly, another participant highlighted the difficulty of cross-checking sources on social media compared to traditional sources:

Much more difficult is if you watch a video on YouTube or if you see on social media all these videos of Syria where it is really difficult to tell if it is really from today. Is it from this area? Is it really a Syrian attachment? It is hard to verify all these propaganda footages (Participant N, 21 May 2013).
In an interesting illustration of the complexity of the use of social media during war and conflict, another participant highlighted the issue of finding quality sources online, suggesting the necessity to have journalists on the ground:

I went in the summer of 2011 to Hamas to see with my eyes the young people who placed videos online during the protests. I established a link with these individuals to understand how they work and gain confidence in the content that they uploaded online. The trusted sources have become sources of trust because I went to see them and I know who they are. That does not mean that all of their content is good. However, I obtained a better view of the scheme and, thus, a better analysis of what they produce and distribute online (Participant F, 12 February 2013).

Another participant illustrated the importance of having journalists on the ground to ensure misleading information spread on social media does not "infect" their reportage with an example:

At the beginning of the protests in Syria, on social media there was a debate on whether the government would have fallen or not. As a journalist, I decided to contact specialists on Syria who told me that it would stand. Then, I also went on the ground and I observed the same. However, it was not the whole speech that was on social media at that time. It is the job of journalists to look for people who know the country and regularly travel there (Participant P, 10 April 2013).

The issue of verification has been addressed by other studies of journalism practices (e.g. Hermida \& Thurman, 2008, Thurman, 2008). According to the findings of Paulussen and Ugille (2008, p. 34) although journalists tend increasingly to use "nonofficial" sources for newsgathering, they face issues of trust and reliability. Even if social media opens the gate to new voices and gives immediate and direct access to sources, the best practice in order to provide accurate coverage appears to be finding the balance between the information spread on social media and that collected "on the ground". This is another way to look at the complementary relationship that can exist between social media and traditional types of reportage. One can complement the limits of the other, showing that both forms of reportage can co-exist in an online digital environment.

Most of the participants agreed that the challenge and benefit of social media resides in its speed of dissemination, which creates a challenge 
for journalists attempting to find quality source material that is also verifiable. One of the participants, for example, said that journalists must apply the same critical analysis to social media as to traditional sources of information, though this is difficult in the 24-hour newsroom:

I think the whole issue of do you trust a source it is not terribly different than as it has use to be before. [...] Quality on social media is really an issue and it is not surprising that it is where the all the things about journalism come up again! It is the training and a set of professionalism that goes into it. [...] Like any new medium that was new at its time, such as the phone, the TV and the radio, it has played a part in these news events. Misinformation has always existed. Today the only difference is that the audience and the speed are not the same (Participant D, 20 March 2013).

As a result of misinformation spreading on social media, hoaxes and incorrect information can quickly become global news. The fake blog, "A Gay Girl in Damascus" that duped many journalists during the "Arab Spring" illustrates this last issue. Amina Araf, an American Syrian lesbian, was considered by many media organisations such as $\mathrm{CNN}$ and $\mathrm{CBC}$ as an "authentic voice" for the movement against the repressive government of Bashar al-
Assad (Bennett, 2011, p. 188). It was found, however, after several months that Amina was a fictional character created by an American student, Tom MacMaster. This example shows how the Internet allows people to easily alter, conceal and manipulate information. It also suggests that traditional journalistic fact-checking and verification practices have to be adapted to more networked approaches in the digital sphere (Bennett, 2011, ibid.).

As an extension of spreading misinformation, social media can be also a fertile ground for pressure groups and governmental organisations, not only to disseminate propaganda and manipulated information, but also to introduce censorship. According to Cottle (2011a), social media tools have been developed by repressive states to target and debilitate the online voices of opposition groups and deny dissident voices communication channels to the outside world. Some agents may take advantage of the openness of social media, spreading misinformation or by undermining the credibility of their opponents. For example, the "Syrian Electronic Army" is a hacker group whose aim has been to bring down, deface, or otherwise target sites that host anti-regime content, as well as targeting news websites (Youmans \& York, 2012). One of the participants gave an example of how social media can be used for propaganda. He described a specific event in Syria during the "Arab Spring":

On the Internet, everything is not clear because behind there is a machine of opinion that is not visible and that is extremely efficient. It is almost a laboratory where people, from pressure groups to governments, know how to make a buzz. [...] The Assad regime used social media to promote his football championship, to show that there was a real life; however, this action was surreal because typically cities such as Homs were at war. The dictatorial regimes wanted to sell an image to the audience. Assad is very powerful because he quickly understood that, on Facebook, there were people in the revolution. Consequently, he has created fake accounts of the revolution to make them lose credibility. He exaggerated the information, and then, he blamed them as liars (Participant K, 12 March 2013).

Nonetheless, opposition groups also understood the potential of social media during the protests in the Middle East. Social media become channels for activism and for spreading messages about state abuses. Real communications strategies were implemented for reaching wide audiences. In this context, the same participant illustrated how the protests were organised in Libya during the "Arab Spring”: 
Before posting a video, there was really an organisation, and there was real activism, which means that the communication was never performed superficially. There were people who had satellite phones and other foreign phone chips. Among these people in Libya, there were those who mastered image and video, and others were just repeaters, which mean that they delivered the content. Facebook pages emerged very quickly with well-organised information that has become real archives (Participant K, 12 March 2013).

Another participant noted something similar but insisted that it is up to the journalists to avoid these risks - that have always been part of the reportage of war and conflict:

Some sites are widely read and have become the subject of takeover. For example, there are sites that have been created and claimed that they were the United Nations, while saying the opposite of what the United Nations would defend in reality. [...] However, you are in charge of the selection and it is your responsibility the kind of reality that you will present through your sources' selection. It really depends on how you build your own picture of reality and what sources you will use to build this reality. Here lies the challenge. The respective players are well aware of the weight of the story. So everyone wants to impose their narrative (Participant J, 19 March 2013).

Journalists can also become targets on social media. Although social media increases the visibility of journalists who promote their stories and reach a wider audience, social media can put the life of correspondents at risk because it is easy to identify and track people on these channels. One of the journalists interviewed clarified this danger by telling a personal account of dangers they faced:

When I went to Syria I had to cancel my social media accounts to preserve my integrity. Immediately after I received a lot of messages from my friends asking me what was happening. I was stuck because I could not reveal the real reason for my act. But I realised that these accounts were a big risk for me. I was very active on them during the "Arab Spring" when I was still in Switzerland. These activities could somehow turn against me when I am on the ground. It was curious to see how it undermined me and at the same time these tools help me a lot because people send me documents, people make me connections with others, I find informants, sometimes they become friends of mine and then I was able to meet them face to face (Participant K, 12 March 2013).
Although "new" technologies and social media have played a key role in the way the "Arab Spring" movement spread, it cannot be the only way to eradicate the "fog of propaganda" (Rodgers, 2011, p. 95). While social media helped citizen engagement during the protests in Middle East, there have also been Internet shutdowns instigated by governmental organisations, and both journalists and cyber-activists have been victims of authoritarian actions (Ghannam, 2011). Social media thus becomes a contested site (Khondker, 2011) where each group tries to impose their narrative. It is professional journalistic practices that becomes the way to protect audiences from possible manipulation and misinformation.

The issues that have been presented so far can thus have an impact on audience engagement with news, especially if the audience questions its trustfulness and unbiasedness. In particular, journalist respondents have stressed that social media can be taken out of context and can also create an illusory perception of participation which can lead to audience disengagement with foreign news. Moreover, social media dissemination of online images can create a superficiality that means news events eventually lose their novelty value. For instance, one of the journalist participants expressed concern about the accessibility of violent videos and images on so- 
cial media such as YouTube which could increase audience indifference to faraway conflicts:

Over time people can become indifferent. I do not think that social media can make this information more concerning. Instead, I am worried about the opposite. When images accumulate, they also lose strength, especially when they are seen on platforms such as YouTube in which there is no context or explanation. Therefore, these images are not of any interest because the users cannot make sense of them. Thus, it is here where the media can be useful" (Participant L, 9 April 2013).

Another journalist respondent even suggested that the overuse of user-generated content like videos would make conflict seem like entertainment instead of news:

I am strongly opposed to the kind of videos on YouTube because I think in a way it is like pornography. People get kick out of it and then they move to the next one. I think photos and stories that really go in depth have a much broader effect than several brutal videos (Participant Q, 24 February 2013).

Instead, another journalist interviewed worried about the illusory participative nature of social media:

The problem is that it has become very easy with social media to believe that users have done something. However, in the end, the users only follow Twitter feeds, which is neither thinking nor being creative; this action does not create any value" (Participant K, 12 March 2013).

Similarly, Gladwell argued that social media encourages "slacktivism", or superficial, minimal effort in support of a cause (Youmans \& York, 2012, p. 316). Although social media has the potential to increase the audience's engagement with more human stories about conflict, lack of context can undermine this potential. It can be envisioned that the "complementary" relationship which could link traditional journalistic practices to social media could overcome this issue. Journalists would thus provide the context which is initially missing on social media to deliver accurate but also personalised information and narratives to their audiences on a global scale. The oversupply of images may generate a superficial understanding of the case which may be supplemented by in-depth analysis and understanding introduced by journalists.
CONCLUSION: THE EFFECTS AND THE FUTURE OF SOCIAL MEDIA USE IN COVERING CONFLICTS

The interviews with Swiss journalists presented in this article illustrate that social media can already be considered an established part of journalists' work environment and norms of practice. However, social media has also complicated the task of journalists, creating issues that journalists must negotiate as part of their work practices in reporting war and conflict. It has been found that social media has a dual character, with features that present simultaneous advantages and disadvantages for mainstream journalists when reporting war and conflict. Taking the "Arab Spring" as basis for the discussion illustrates that although social media has been a key source of information, and has mostly enabled journalists to deliver an accurate and a broad coverage of events, limits of its usage have also arisen. It can be concluded that social media can complement traditional media because it works as an alert and allows direct access to sources and images from remotes areas. The dynamism that these channels allow opens new possibilities for fast news dissemination, pluralised voices in reportage and extended audience 
reach. However, the reporters also have to face the drawbacks that go with fast, multi-medium and multi-sourced information, especially in terms of verification of information and contextualisation. The Swiss journalists interviewed suggested that much of the content they encountered on social media was out of context and lacked in-depth explanation. This highlights the need for journalists to act with the same kind of gate-keeping attitude they bring to traditional reportage.

Relying on their professional principles, journalists can be the gatekeepers of social media information, verifying the information spread on these channels, adding value and pinpointing relevant and accurate content, as well as ensuring quality. According to Hermida et al. (2012, p. 11), "in a networked media environment, the journalist emerges as a central node trusted to authenticate, interpret, and contextualise information flows on social awareness streams, drawing on a distributed and networked newsroom where knowledge and expertise are fluid, dynamic and hybrid". To avoid the risks present in social media, journalists are required to find equilibrium between editorial choices and freedom of information, between traditional ground research and online research. Media professionals can take the best from the information delivered on social media as well as from the capacities that these tools offer in terms of access to sources and reaching international audiences. Traditional media practices can merge with social media in order to make social media stand as a positive vehicle to cover war and conflict and let foreign news gain its deserved attention. Innovation is situated at the level of practices and working processes. In line with Roginsky's findings (2014, p. 119), social media technology creates new conventions and practices of communication, in particular between the user and the journalist that had not been observed previously. While the results of this research cannot be generalized beyond the scope of Swiss journalists, it could be applicable to newsrooms that follow a similar liberal traditional of journalism. Some comparison with social media usage in several newsrooms from very different countries which have diverse degrees of freedom of expression and technology skills should nonetheless be added to this preliminary research. Network analysis might also offer an interesting perspective on how (mis)information spreads on these channels. Other such studies could examine the different relationships that link the various cyber-actors (e.g. journalists, politicians, NGOs and activists) as well as the complexity and nuances of the practice of journalism, and its organisational and institutional policies. Further research should also inves- tigate if social media affects the attitude that audiences form about war and conflict as well as how social media impacts the collective memory of war and conflict.

\section{ACKNOWLEDGMENT}

This project was sponsored by the Swiss National Science Foundation (Grant P1NEP1_151907). 


\section{REFERENCES}

Allan, S., Sonwalkar, P. \& Carter, C. (2007). Bearing Witness: Citizen Journalism and Human Rights Issues. Globalisation, Societies \& Education 5(50), 373-89.

Andén-Papadopoulos, K. (2009). Body Horror on the Internet: US Soldiers Recording the War in Iraq and Afghanistan. Media, Culture \& Society 31(6), 921-38.

Arksey, H. \& Knight, P. (1999). Interviewing for social scientists: An introductory resource with examples. London: Sage Publications.

Banks, J. (2013). Co-Creating Videogames. London: Bloomsbury Academic.

Bennett, D. (2011). A "Gay Girl in Damascus", the Mirage of the "Authentic Voice" and the Future of Journalism. In J. Mair and R. L. Keeble (eds.), Mirage in the desert? Reporting the "Arab Spring" (pp. 187-195). Bury, St Edmunds: Abramis Academic Publishing.

Bossio, D. \& Bebawi, S. (2013). War of Worlds? Alternative and Mainstream Journalistic Practices in Coverage of the "Arab Spring" Protests. In J. E. Hayes, K. Battles and W. Hilton-Morrow (eds.), War of the Worlds to social media (pp. 189-210). New York: Peter Lang.
Bromley, M. (2004). The Battlefield is the Media: War reporting and the Formation of National Identity in Australia - From Belmont to Baghdad. In S. Allan and B. Zelizer (eds.), Reporting War (pp. 224-244). London: Routledge.

Bruns, A. (2008). Blogs, Wikipedia, Second Life, and Beyond: From Production to Produsage. New York: Peter Lang.

Bruns, A. (2014). Media Innovations, User Innovations, Societal Innovations. The Journal of Media Innovations 1(1), 13-27.

Campbell, F. (1997). Journalistic construction of news: information gathering. New Library World 98(2), 60-4.

Cottle, S. (2008). Global Crisis Reporting. Journalism in the Global Age. Maidenhead, UK: Mc Graw-Hill Education, Open University Press.

Cottle, S. (2011a). Afterword - Media and the Arab Uprisings of 2011. In S. Cottle and L. Lester (eds.), Transnational Protests and the Media (pp. 293304). New York: Peter Lang Publishing.

Cottle, S. (2011b). Cell phones, Camels and the Global Call for Democracy. In J. Mair and R. L. Keeble (eds.), Mirage In the Desert? Reporting the "Arab Spring” (pp. 196-210). Bury, St Edmunds: Abramis Academic Publishing.
Dogruel, L. (2014). What is so Special about Media Innovations? A Characterization of the Field. The Journal of Media Innovations 1(1), 52-69.

Eltantawy, N. \& Weist, J. B. (2011). Social Media in Egyptian Revolution: Reconsidering Resource Mobilization Theory. International Journal of Communication 5, 1207-24.

Gaunt, P. (1990). Choosing the News: The Profit Factor in News selection. New York: Greenwood Press.

Ghannam, J. (2011). Social Media in the Arab World: Leading up to the Uprisings of 2011. Center for In ternational Media Assistance. Washington, D.C..

Gray, H. C. (1997). Postmodern war. London: Guilford.

Hermida, A. (2009). The blogging BBC: Journalism blogs at "the world's most trusted news organisation”. Journalism Practice 3(3), 268-84.

Hermida, A. (2010). Twittering the news: The emergence of ambient journalism. Journalism Practice 4(3), 297-308

Hermida, A. (2012). Tweets and truth: Journalism as a discipline of collaborative verification. Journalism Practice 6(5-6), 659-68.

Hermida, A. \& Thruman, N. (2008). A Clash of Cultures: the integration of user-generated content within professional journalistic frameworks at British newspaper websites. Journalism Practice 2(3), $343-56$. 
Hermida, A., Lewis, S. C. \& Zamith, R. (2012). Sourcing the Arab Spring: A case study of Andy Carvin's sources during the Tunisian and Egyptian Revolutions. Paper presented at the international symposium on online journalism, Austin, TX, 20 April.

Hodgkins, J. (2002). In the wake of Desert Storm: A consideration of modern World War II films. Journal of Popular Film and Television 3o(2), 74-84.

Hycner, R. H. (1985). Some guidelines for the phenomenological analysis of interview data. Human studies $8(3), 279-303$

Ibrahim, Y. (2010). Distant Suffering and Postmodern Subjectivity: the Communal Politics of Pity. Nebula $7(1-2), 112-35$

Joseph, S. (2012). Social media, political change, and human rights. Boston College International \& Comparative Law Review 35(1), 145-88.

Kellner, D. M. (1992). The Persian Gulf TV War. Boulder, CO: Westview.

Kendrick, M. (1994). The never again narratives: political promise and the videos of operation desert storm. Cultural Critique, 129-47.

Khondker, H. H. (2011). Role of the new media in the Arab Spring. Globalizations 8(5), 675-79.

Lee-Wright, P., Philips, A. \& Witschge, T. (2012). Changing Journalism. London and New York: Routledge.
Moeller, S. D. (1999). Compassion Fatigue: How the Media Sell Disease, Famine, War and Death. New York: Routledge.

Morrison, D. E. (1994). Journalists and the Social Construction of War. Contemporary Record 8(2), 305-20.

Mortensen, M. (2011). The eyewitness in the age of digital transformation. In K. Andén-Papadopoulos and M. Pantti (eds.), Amateur Images and Global News (pp. 63-75). Bristol, UK: Intellect Books.

Nygren, G. (2014). Multiskilling in the Newsroom: Deskilling or Re-skilling of Journalistic Work? The Journal of Media Innovations 1(2), 75-96.

O'sullivan, J. \& Heinonen, A. (2008). Old values, new media: Journalism role perceptions in a changing world. Journalism Practice 2(3), 357-71.

Otto, R. \& O Meyer, C. (2012). Missing the story? Changes in foreign news reporting and their implications for conflict prevention. Media, War \& Conflict 5(3), 205-21.

Paulussen, S. \& Ugille, P. (2008). User generated content in the newsroom: Professional and organisational constraints on participatory journalism. Westminster Papers in Communication \& Culture 5(2), 24-41.
Reese, S. D. (2011). On Anti-Iraq War Protests and the Global News Sphere, In S. Cottle and L. Lester (eds.), Transnational Protests and the Media (pp. 74-86). New York: Peter Lang Publishing.

Robinson, P., Goddard, P., Parry, P. \& Murray C. (2009). Testing models of media performance in wartime: UK TV news and the 2003 invasion of Iraq Journal of Communication 59(3), 534-63.

Robinson, P., Goddard, P.; Perry, K. \& Murray, C. (2010). Pockets of resistance: British News media, War and Theory in the 2003 Invasion of Iraq. Manchester: Manchester University Press.

Rodgers, J. (2011). The fog of propaganda: Attempts to influence the reporting of the 'Arab Spring' and how journalists should see through them. In J. Mair and R. L. Keeble (eds.), Mirage In the Desert? Reporting the 'Arab Spring' (pp. 94-100). Bury, St Edmunds: Abramis Academic Publishing.

Roginsky, S. (2014). Social Network Sites: An Innovation Form Of Political Communication? A SocioTechnical Approach To Media Innovation. The Journal of Media Innovations 1(2), 97-125

Sambrook, R. (2010). Are Foreign Correspondents Redundant? The Changing Face of International News. Oxford: Reuters Institute for the Study of Journalism. 
Sylvester, C. (2011). Experiencing War. Oxford: Routledge.

Taylor, P. (1997). Global communications, international affairs and the media since 1945. London: Routledge.

Thelwall, M. \& Stuart, D. (2007). RUOK? Blogging communication technologies during crises. Journal of Computer of Mediated Communication 12(2), 523-548.

Thurman, N. (2008). Forums for citizen journalists? Adoption of user generated content initiatives by online news media. New Media \& Society 1O(1), $139-57$

Tuchman, G. (1978). Making News: A Study in the Construction of Reality. New York: The Free Press.
Tumber, H. (2009). Covering war and peace. In K. Wahl-Jorgensen and T. Hanitzsch (eds.), The Handbook of Journalism Studies, (pp. 386-97). New York: Routledge.

Youmans, W. L. \& York, J. C. (2012). Social media and the activist toolkit: User agreements, corporate interests, and the information infrastructure of modern social movements. Journal of Communication 62(2), 315-29.

Zelizer, B. \& Allan, S. (2011). Journalism after September 11. New York: Taylor \& Francis.

Zhang, S. I. (2013). The new breed of Chinese war correspondents: Their motivations and roles, and the impact of digital technology. Media, War \& Conflict 6(3), 311-25. 